\title{
High morphological and genetic variabilities of Ochlerotatus scapularis, a potential vector of filarias and arboviruses
}

\author{
Vivian Petersen ${ }^{1,2^{*}}$, Mariana Devicari ${ }^{1,2}$ and Lincoln Suesdek $k^{1,2,3}$
}

\begin{abstract}
Background: Ochlerotatus scapularis is a potential vector of filarias and arboviruses in the Neotropics. This species was once typically associated with sylvatic environments; however, cases of synanthropy and urbanization of this species have been increasingly reported in southeast Brazil. Despite the medical relevance of Oc. scapularis, its populational variability is not yet known. To our knowledge, this is the first report describing the morphological and genetic variabilities of this species.
\end{abstract}

Methods: Population samples were characterized using the cytochrome oxidase subunit I (COI) mitochondrial gene and wing geometrics. Adult mosquitoes were collected from five sampling sites from remnants of the Atlantic forest embedded in the urban or rural areas of southeast Brazil.

Results: In the 130 individuals analyzed, 46 COI haplotypes were detected. Haplotype diversity was high and ranged from 0.66 to 0.97 . Six haplotypes were present in $61 \%$ of the individuals, whereas the remaining haplotypes were less frequent (39\%). Wing shape was also highly polymorphic. Differentiation of populations across sampling sites according to genetic distances $\left(F_{s t}=-0.009\right.$ to 0.060$)$ and morphological distances $\left(Q_{s t}=0.47\right)$ indicated that populations were not identical. No correlations were noted for phenetic and genetic diversities $(p=0.19)$ or for genetic or phenetic distances with geographical distances ( $p=0.2$ and $p=0.18$, respectively).

Conclusions: Our study results suggest that Oc. scapularis has a rich genetic patrimony, even though its habitat is fragmented. Implications of such genetic richness with respect to vectorial competence, plasticity, and ability to exploit urbanized areas need to be further investigated.

Keywords: Plasticity, Population structure, Haplotype diversity, Morphological diversity

\section{Background}

Ochlerotatus scapularis (Rondani 1848) is a Neotropical culicid widely distributed in the southeastern region of Brazil [1]. This mosquito species is frequently found in remnants of the Atlantic Forest biome embedded in large rural or urban locations [2].

Nonetheless, in southeast Brazil, this species has been reported to occur in sylvan rural and urban ecotones $[3,4]$ that are inhabited by millions of people. Remarkably, Oc. scapularis can be synanthropic and enter human dwellings [5], and has been increasingly reported to

\footnotetext{
* Correspondence: var_petersen@hotmail.com

${ }^{1}$ Instituto Butantan, São Paulo, Brazil

${ }^{2}$ Biologia da Relação Patógeno-Hospedeiro-Universidade de São Paulo, São Paulo, Brazil

Full list of author information is available at the end of the article
}

inhabit urban parks. Although the larvae of Oc. scapularis preferentially develop in natural temporary pools of water in the soil, they might also exploit permanent natural or artificial water containers [6].

The concurrence of insects and humans in this case is particularly problematic, because this mosquito has vectorial competence for several human and animal pathogens such as Rocio virus [7]. Oc. scapularis was possibly involved in the transmission of Rocio encephalitis virus in the State of São Paulo (southeast Brazil). This human encephalitis epidemic [8] occurred between 1974 and 1978 in 20 municipalities of São Paulo, in which more than 1,000 people were infected, hundreds of deaths occurred, and an estimated 200 sequelae cases were reported. 
Outside southeast Brazil, this mosquito might also be a vector of the worms Dirofilaria immitis [9] and Wuchereria bancrofti [10], and the viruses Venezuelan Equine Encephalitis [11], Ilheus [12], and Melao [13]. The epidemiological importance of this mosquito vector is reinforced by its gonotrophic discordance: as females might need more than one blood repast during a single gonotrophic cycle, this increases their contact with possible hosts [14].

Heretofore, some key investigations such as biological variability of Oc. scapularis had not yet been performed. Even the remarkable population polymorphisms regarding chaetotaxy and genitalia, which were empirically reported by Arnell [15] and Forattini [1], have not been quantitatively investigated.

To better understand the biology of Oc. scapularis, we, for the first time, investigated the populational variability of this species. We then compared population samples collected from some southeast Brazil municipalities with epidemiologically relevant conditions by using largely used genetic (mitochondrial COI gene) and morphological (wing geometry) markers.

\section{Methods}

\section{Collection of mosquitoes}

Sampling sites were located adjacent to the remnants of the southeastern Brazilian Atlantic Forest. Between 2007 and 2011, adult mosquitoes were collected using a portable insect aspirator from five locations (map with geographic coordinates shown in Figure 1): Parque Ecológico do Tietê (PET), Butantan neighborhood (BUT), Tremembé (TRE), Itaboraí (ITA), and Pariquera-Açu (PAR). The epidemiological relevance of the sampling locations is that some sites are urban parks located in areas inhabited by several millions of people, such as PET and BUT in São Paulo city (State of Sao Paulo). PAR was affected by the Rocio outbreak in 1974; it is a small urban locality surrounded by rural areas with buffalo ranches and rice paddies. TRE and ITA are located near rural areas inhabited by several thousands of people.

Owners of private properties and administrators of public parks authorized the mosquito collection. More collection details are shown in Table 1. Mosquitoes were identified down to the species level using taxonomic keys for female adult mosquitoes [1], and were individually placed in $1.5 \mathrm{ml}$ microtubes with silica gel beads at room temperature until DNA and wing extraction.

\section{DNA amplification and sequencing}

A partial fragment of the mitochondrial gene cytochrome oxidase subunit I (COI) of the five populations was comparatively analyzed. Extraction of DNA was performed according to the Vidal \& Suesdek [16]. The COI gene was chosen because it is a sensitive indicator of spatial genetic
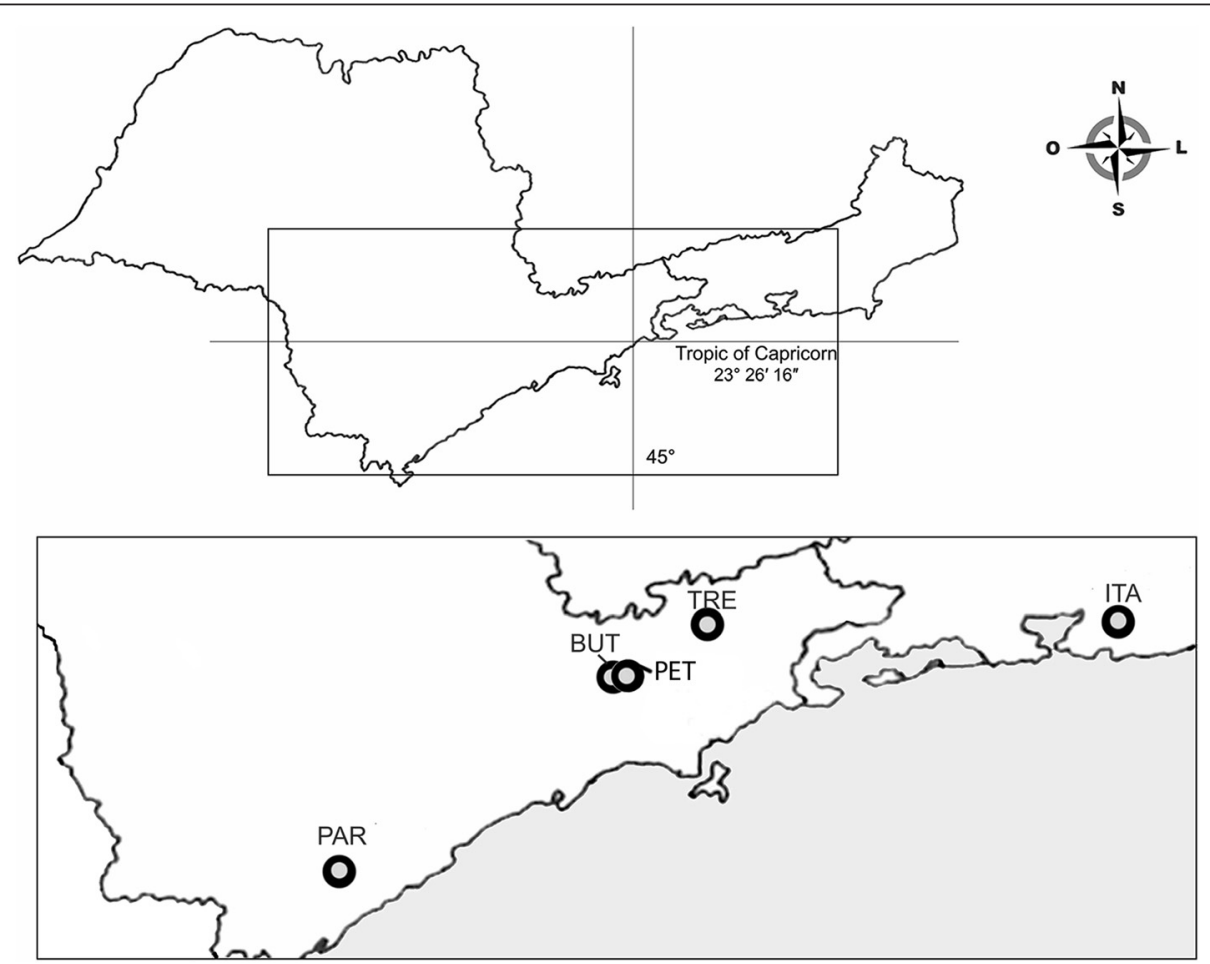

Figure 1 Map of São Paulo and Rio de Janeiro states (above). In detail, the four collecting sites of Oc. scapularis samples (below). More details shown in Table 1. 
Table 1 Data of five samples Oc. scapularis collected in Brazil

\begin{tabular}{|c|c|c|c|c|c|c|}
\hline Sample ID & Municipality & Locality & $\begin{array}{l}\text { Number of } \\
\text { samples (COI) }\end{array}$ & $\begin{array}{l}\text { Number of samples } \\
\text { (morphometrics) }\end{array}$ & Data & Geographic coordinates \\
\hline \multirow[t]{2}{*}{ PET } & \multirow[t]{2}{*}{ São Paulo } & \multirow[t]{2}{*}{ Parque Ecológico do Tietê } & \multirow[t]{2}{*}{34} & \multirow[t]{2}{*}{29} & \multirow[t]{2}{*}{ April/2011 } & $23^{\circ} 29^{\prime} 15^{\prime \prime} \mathrm{S}$ \\
\hline & & & & & & $46^{\circ} 31^{\prime} 90^{\prime \prime} \mathrm{W}$ \\
\hline \multirow[t]{2}{*}{ BUT } & \multirow[t]{2}{*}{ São Paulo } & \multirow[t]{2}{*}{ Horto Instituto Butantan } & \multirow[t]{2}{*}{10} & \multirow[t]{2}{*}{39} & \multirow[t]{2}{*}{ February/2009 } & $23^{\circ} 32^{\prime} 44^{\prime \prime S}$ \\
\hline & & & & & & $46^{\circ} 43^{\prime} 39^{\prime \prime} \mathrm{W}$ \\
\hline \multirow[t]{2}{*}{ ITA } & \multirow[t]{2}{*}{ Itaboraí } & \multirow[t]{2}{*}{ Pasture } & \multirow[t]{2}{*}{36} & \multirow[t]{2}{*}{30} & \multirow[t]{2}{*}{ March/2011 } & $22^{\circ} 44^{\prime} 51^{\prime \prime S}$ \\
\hline & & & & & & $42^{\circ} 51^{\prime} 21^{\prime \prime} \mathrm{W}$ \\
\hline \multirow[t]{2}{*}{ TRE } & \multirow[t]{2}{*}{ Tremembé } & \multirow[t]{2}{*}{ Fazenda Santa Cecília } & \multirow[t]{2}{*}{29} & \multirow[t]{2}{*}{30} & \multirow[t]{2}{*}{ November/2010 } & $22^{\circ} 57^{\prime} 12^{\prime \prime} \mathrm{S}$ \\
\hline & & & & & & $45^{\circ} 32^{\prime} 28^{\prime \prime} \mathrm{W}$ \\
\hline \multirow[t]{2}{*}{ PAR } & \multirow[t]{2}{*}{ Pariquera-Açu } & \multirow[t]{2}{*}{ Fazenda experimental } & \multirow[t]{2}{*}{21} & \multirow[t]{2}{*}{25} & \multirow{2}{*}{$\begin{array}{l}\text { December/2007, } \\
\text { March 2008,May } 2009\end{array}$} & $24^{\circ} 42^{\prime} 37^{\prime \prime} \mathrm{S}$ \\
\hline & & & & & & $47^{\circ} 53^{\prime} 2^{\prime \prime} \mathrm{W}$ \\
\hline
\end{tabular}

structure $[17,18]$ and has been successfully used to study intraspecific genetic variation in insects [19-21]. Sample sizes in this analysis were as follows (Table 1): PET, ITA, TRE, PAR, and BUT. The COI gene was amplified using polymerase chain reaction (PCR) [22].

PCR amplicons of COI were electrophoresed in 1.0\% agarose gel in TAE buffer (0.04 Tris buffer, $0.05 \mathrm{M}$ sodium acetate, $0.01 \mathrm{M}$ EDTA $\mathrm{pH} 8.0$ (TAE). We used $2 \mu \mathrm{l}$ of the PCR amplified, add $1 \mu \mathrm{l}$ of $6 \times$ DNA Loading Dye $(0.1 \%$ bromophenol and $30 \%$ glycerol $)$ and $1 \mu \mathrm{l}$ gel red. The primers 5'-LCO1490 GGTCAACA AATCATAAAGATATTGG-3' and HC02198 5'-TAAA CTTCAGGGTGACCAAAAAATCA-3' were used for sequencing. For the final reaction $10 \mu \mathrm{l}$ were added: $2 \mu \mathrm{l}$ of $5 \times$ sequencing buffer, $3.6 \mathrm{pmol}$ of primer (Forward or reverse), 0.25 of the Big Dye, 10-50 ng of DNA and ultrapure water. Reaction conditions were as follows: $96^{\circ} \mathrm{C}(15 \mathrm{~s}), 50^{\circ} \mathrm{C}(15 \mathrm{~s})$ and $60^{\circ} \mathrm{C}(4 \mathrm{~min})$ for 25 cycles [23]. For the sake of accuracy, amplicons of each individual were sequenced twice and high fidelity Platinum $^{\odot}$ Taq DNA Polymerase was used.

In order to quantify genetic polymorphism and compare across populations, the COI gene sequences were aligned in ChromasPro 2.4 [24]. Next, the number of haplotypes $(\mathrm{H})$, haplotype diversity $(\mathrm{h})$, and nucleotide diversity ( $\pi)$ were estimated using software DNAsp 5.0 [25]. The neutrality tests Tajima's and Fu's Fs were performed using Arlequin 3.11 [26] for testing whether the mutations were neutral. Fu's Fs test is very sensitive to population expansion. The genetic differentiation index $\left(\mathrm{F}_{\mathrm{st}}\right)$ test for short divergence time was performed using Arlequin 3.11 software. The genetic distance among populations of Oc. scapularis was calculated using the Kimura 2-parameter (K2P) by using software Mega version 5.1 [27]. A haplotype network of COI sequences was constructed using a parsimony framework by using TCS 1.21 software [28], and the network was edited using the Image program. The cladogram of haplotypes was constructed using Mr Bayes software with 10,000,000 generations.

\section{Morphometric analyses of the wing}

Wings are good biological markers owing to its bidimensionality and heritability [29]. Geometric morphometrics was chosen to describe the wings of Oc. scapulars because it is a sensitive and cheap technique, which has been increasingly used to describe inter and intraspecific variability [16,29-32].

The geometry of (right) wings of females from the five populations was comparatively analyzed. Samples sizes were PET, ITA, TRE, PAR, and BUT (Table 1). Geometric morphometrics reported by Vidal \& Suesdek [18] were used. Images of the wings were captured using a Leica 320 digital camera coupled with a Leica S6 stereoscope. We digitized 18 landmarks using TpsDig V.1.40. Procrustes superimposition of raw positional coordinates and shape coordinates (to assess the wing shape) was calculated using computer programs TpsUtil 1.29 and TpsRelw 1.39 [33]. The principal components (PCs) of shape coordinates and discriminant analyses of the samples based on PCs were calculated using Morphoj 1.05 software [34] for evaluating the populational degree of similarity among the five populations studied.

Morphological diversity was estimated using the "amount of dispersion" of individuals in the morphospace of PCs. Such dispersion was calculated as follows: plots in the morphospace of PCs (each corresponding to a single mosquito) were digitized using TpsDig software (as performed for wings) in order to register their positional coordinates in an imaginary Cartesian plane. The centroid size of a set of individuals (a population) was calculated using TpsRelW software. Such centroid size was then considered as an indicator of the morphological diversity of a population. Theoretically, the amount of dispersion of individuals (of a single set) in the morphospace of PCs is proportional to the morphological variability 
of that set (see Additional file 1: Figure S1 for more details).

After the allometric effect on wing shape was estimated and removed, wings were compared among populational samples by using discriminant analysis [35]. Mahalanobis distances ( $p$-value from non-parametrical tests with 10,000 permutation rounds) were used to construct phenetic trees by using the algorithm Neighbor-Joining (PAUP [36] and COV softwares [37]).The correlation between geographic and phenetic distances was also statistically tested using Pearson's correlation in Statistica 7 [38].

Wing images of other species (Aedes aegypti, Aedes albopictus, Anopheles cruzii, Anopheles homunculus, Culex nigripalpus, and Culex quinquefasciatus) were also included in one of the comparative morphometric analyses. Those species were collected with a similar procedure of Oc. scapularis in locations mentioned in the Additional file 2: Table S1.

\section{Results}

\section{Genetic analyses}

We obtained a 448-bp fragment that is located in the barcode region of the COI gene and is also known to be highly variable and indicative of populational genetic polymorphisms $[39,40]$. In the 130 analyzed individuals, $46 \mathrm{COI}$ haplotypes (GenBank accession number KM115416-61) were identified; 38 sites in the 448-bp fragment were variable. The statistical analysis of the genetic parameters is summarized in Table 2. The overall haplotype diversity was high (0.91), whereas the genetic pairwise distances among populations (Kimura 2-parameter) were low, ranging from 0.0054 to 0.0091 (Table 3).

The similarities among haplotypes were depicted in a network (Figure 2). Two haplotypes (H1 and H5), which were the most frequent, were shared by all population samples and were present in $37 \%$ of the individuals, whereas the other moderately frequent haplotypes ( $\mathrm{H} 6, \mathrm{H} 7, \mathrm{H} 9$ and $\mathrm{H} 20$ ) were shared by $3-4$ populations and were present in $23 \%$ of the individuals. The remaining 40

Table 2 Summary statistics for polymorphisms of five Oc. scapularis populations

\begin{tabular}{llllllll}
\hline & $\mathbf{N}$ & $\begin{array}{l}\text { Unique } \\
\text { haplotypes }\end{array}$ & $\mathbf{H}$ & $\mathbf{h}(\mathrm{SD})$ & $\boldsymbol{\pi}(\mathrm{SD})$ & $\mathbf{D T}$ & $\mathrm{FS}$ \\
\hline PET & 34 & 5 & 16 & 0.8841 & 0.007182 & -1.26855 & $-6.62988^{*}$ \\
ITA & 36 & 8 & 18 & 0.9238 & 0.008977 & -0.92875 & $-6.92782^{*}$ \\
TRE & 29 & 12 & 23 & 0.9704 & 0.008856 & -1.24190 & $-19.15227^{*}$ \\
PAR & 21 & 3 & 9 & 0.8476 & 0.006392 & -0.52875 & -0.62766 \\
BUT & 10 & 3 & 5 & 0.6667 & 0.004395 & -0.85010 & -0.97655 \\
\hline
\end{tabular}

$\mathrm{N}=$ Number of sequences used; $\mathrm{H}=$ Number of haplotypes, $\mathrm{h}(\mathrm{SD})=$ Haplotype diversity; $\pi(\mathrm{SD})=$ Nucleotide diversity, $\mathrm{DT}=$ Tajima's $\mathrm{D}$ test; $\mathrm{FS}=$ Fu's Fs test statistic; ${ }^{*}$ significant values at $\mathrm{p}<0.05$.
Table 3 K2P Genetic distance between five Oc. scapularis populations

\begin{tabular}{lllll}
\hline & PET & ITA & TRE & PAR \\
\hline ITA & 0.0086 & - & & \\
TRE & 0.0081 & 0.0091 & - & \\
PAR & 0.0067 & 0.0079 & 0.0075 & - \\
BUT & 0.0069 & 0.0074 & 0.0069 & 0.0054 \\
\hline
\end{tabular}

haplotypes appeared in low frequencies and were mostly exclusive to one population (1-3 individuals each).

$\mathrm{F}_{\mathrm{st}}$ scores ranged from -0.009 to 0.060 and were consistent with a weak or no population structure (Table 4), and the highest estimated divergence (between ITA and BUT) was only moderate. Some $F_{\text {st }}$ scores, although negative, were not significantly different from zero.

\section{Morphometric analyses}

Discriminant analysis of the shape PCs, represented by canonical variables, revealed a complete discrimination between ITA and BUT populations and slight differences among the other populations: polygons (populations) in the morphospace overlapped partly (Figure 3 ). Although the slight populational differentiation noted, Mahalanobis distances were statistically significant (nonparametric $p<0.0001$ ) for all pairwise comparisons, which is ordinarily indicative of a population structure. The $\mathrm{Q}_{\mathrm{st}}$ estimator of phenetic populational differentiation scored 0.47 , a value as high as to corroborate the presence of population structure [29].

The phenogram of Mahalanobis distances determined on the basis of wing shape (Figure 4) and results of correlation analysis did not reveal any significant correlation between phenetic and geographic distances $(\mathrm{r}=0.46 \mathrm{p}=0.18)$.

Figure 5 shows that morphological diversity (estimated using the size of the spread of individuals in the morphospace of PCs) was variable, but its scores varied less than those of genetic diversity (estimated using haplotype diversity). No significant correlation was found between these 2 diversity estimators $(\mathrm{r}=0.69, \mathrm{p}=0.19)$. Morphological diversity of Oc. scapularis was also high when compared to those of 6 other culicid species (Figure 6).

\section{Discussion Variability}

A high haplotype diversity (mean $=0.91$ ) was noted in the five populations. Such high polymorphism might indicate that these populations have not been recently affected by a bottleneck, despite the dramatic fragmentation of the Atlantic Forest during the past 300 years [41]. Similarly, the negative values of Tajima's and Fu's Fs for all populations suggest that these populations might be expanding or have a selective sweep of their COI gene [42,43]. Similar patterns and interpretations were reported in a population study of 


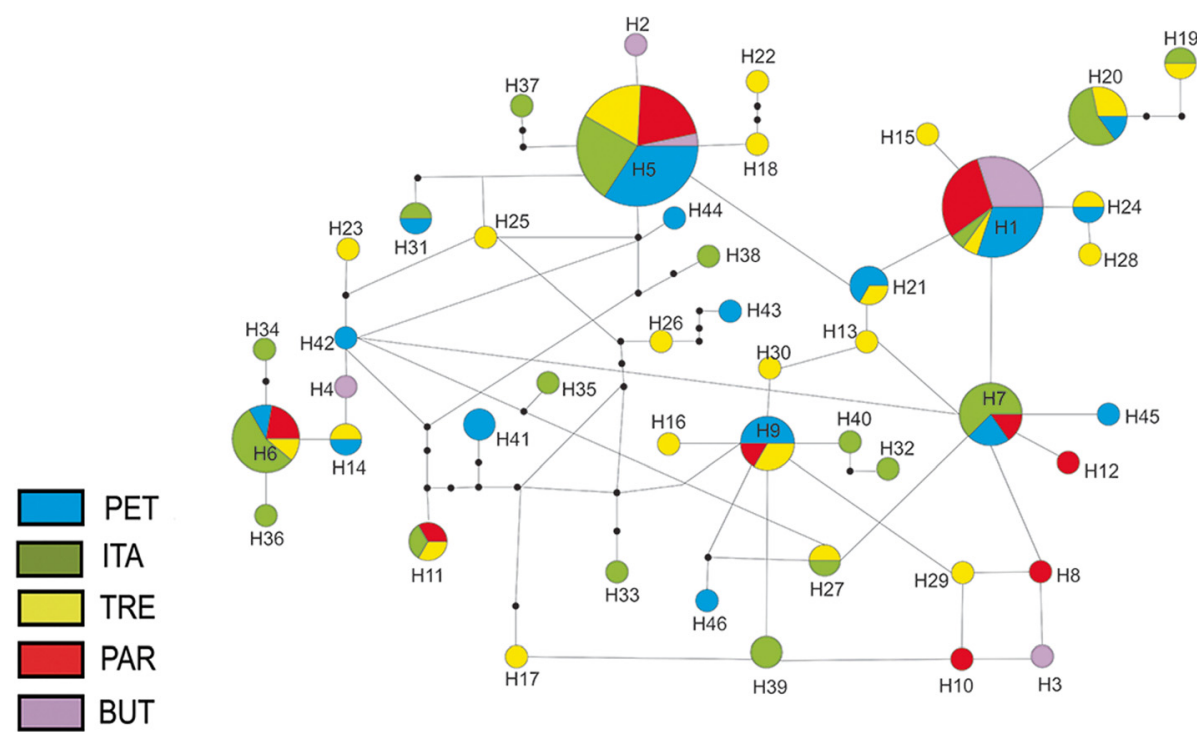

Figure 2 Haplotype networks based on COI gene in five populations of Oc. scapularis from Brazil. The size of each circle or circular sector is proportional to the number of individuals sharing that haplotype; the smallest circle corresponds to a single individual.

the culicid Anopheles lesteri, which was determined using COI gene polymorphism [44]. These authors obtained only negative values in neutrality tests and suggested that the populations under study were most likely undergoing expansion.

Oc. scapularis is naturally infected with Wolbachia (Noguera \& Suesdek, unpublished data), and the presence of this endosymbiotic bacterium could decrease the number of haplotypes, as documented by Morais et al. [45] in Culex quinquefasciatus. However, the COI gene in Oc. scapularis still displays a high rate of polymorphism. Another Neotropical species with high genetic polymorphism is An. cruzii Dyar \& Knab, which presented 60 haplotypes in 96 individuals, with a haplotypic diversity $=0.98$ [46]. Nevertheless, large haplotype diversity is not commonly reported in Culicidae. For example, only 12 COI haplotypes were found in 88 individuals of An. darlingi Root (a predominant species in South America), from five locations in Colombia [47]. Another example is Ae. albopictus (Skuse), a species evolutionarily close to Oc. scapularis, which has only 16 haplotypes from 377 specimens [48]. Thus, Oc. scapularis appears to be a

Table 4 Pairwise $F_{\text {st }}$ estimates between five Oc. scapularis populations

\begin{tabular}{lllll}
\hline & PET & ITA & TRE & PAR \\
\hline ITA & 0.04433 & - & & \\
TRE & -0.00946 & 0.00328 & - & \\
PAR & -0.02371 & 0.01580 & -0.01997 & - \\
BUT & -0.01310 & $0.06021^{*}$ & 0.01052 & -0.02957
\end{tabular}

*Indicates moderate structure ( $P$ value significant at $<0.05$ ). highly genetically diverse species. We find it improbable that such discrepancy is because of experimental errors or sampling biases because amplifications/sequencing were replicated and the high genetic diversity is consistent with the high morphological diversity observed.

In addition, the morphological diversity of Oc. scapularis was high in all populations. Even other Neotropical sylvatic species (An. homunculus, An. cruzii, Cx. nigripalpus, and Ae. albopictus) showed lesser diversity than Oc. scapularis.

The removal of both isometric and allometric effects of size permitted us to assess the wing geometry almost purely based on its shape. Considering that wing shape of culicids is mainly determined by quantitative polygenic heritage [29] and was highly variable in Oc. scapularis, we believe that wing shape may be a morphological indicator of genetic variability. A similar interpretation was given in studies of Culex coronator Dyar \& Knab [30].

\section{Population structure}

Bayesian phylogenetic inference derived using COI data (data not shown) failed to show reliable clusters of populations, and thus, do not suggest the presence of a population structure. Although the interpretations of the phylogenetic relationships among haplotypes cannot yet be inferred, the major haplotypes $\mathrm{H} 1$ and H5 seem to be closer to a common ancestor. All or most of the populations shared $\mathrm{H} 1$ and $\mathrm{H} 5$, and the interpopulation differentiation was low. In fact, all $F_{\text {st }}$ scores were below 0.07, and gene flow was estimated to be significant. The absence of correlation between genetic and geographical $(\mathrm{p}=0.2)$ distances is also consistent with a weak population structure. 


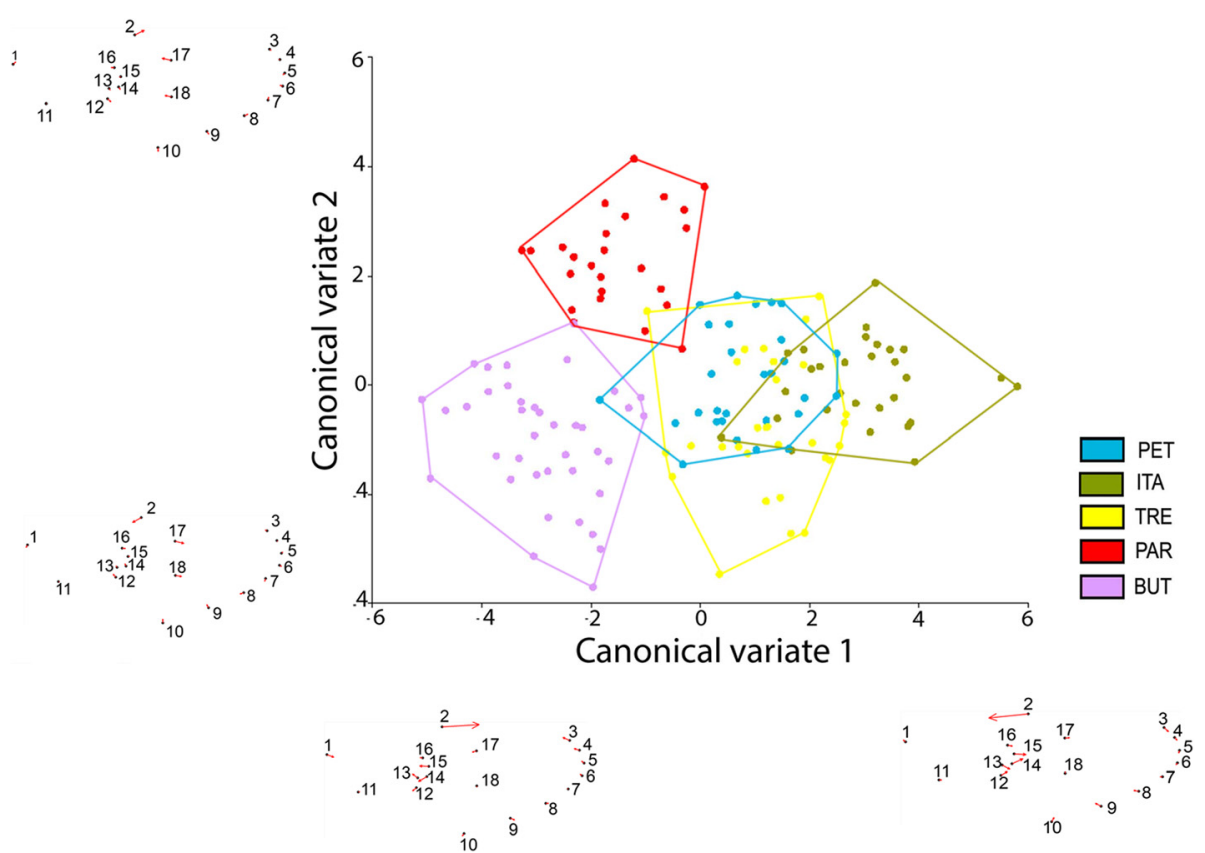

Figure 3 Morphological space of canonical variates resulting from the comparison among the five populations of Oc. scapularis. The 4 vectorial diagrams along the morphospace are "Thin plate splines" resulting from regression of canonical scores against shape components.

As $\mathrm{H} 1$ and $\mathrm{H} 5$ were the only haplotypes shared by all populations, they might be considered as the remnants of an ancestral polymorphism. This might be an alternative explanation to interpopulation migration, as revealed in studies of the retention of mitochondrial haplotypes in Anopheles arabiensis Patton and Anopheles gambiae Giles [49].

Remarkably, suitable habitats for Oc. scapularis (rural areas, forest borders, and parks) are discontinuous across southeast Brazil. Even in the populational sample obtained from BUT, where collections were made from the smallest forest remnant $\left(\sim 40,000 \mathrm{~m}^{2}\right)$ surrounded by densely urbanized neighborhood, high genetic and phenetic diversities were noted. The observed pattern of population similarity could be explained by the retention of ancestral polymorphisms or current passive migration, or might merely be a result of the colonization history. Among Culicidae, another species that has maintained interpopulation similarity despite wide geographical distribution and habitat discontinuity, is the malaria vector An. darlingi [50].

Wing shape characteristics provided some evidence of an incipient population structure, coherently supported by canonical variates morphospace, Mahalanobis distances, and Qst. The different Mahalanobis distance scores can be interpreted as different degrees of structuration, but the underlying factors to this heterogeneity are still unknown. The phenogram of morphological distances showed that

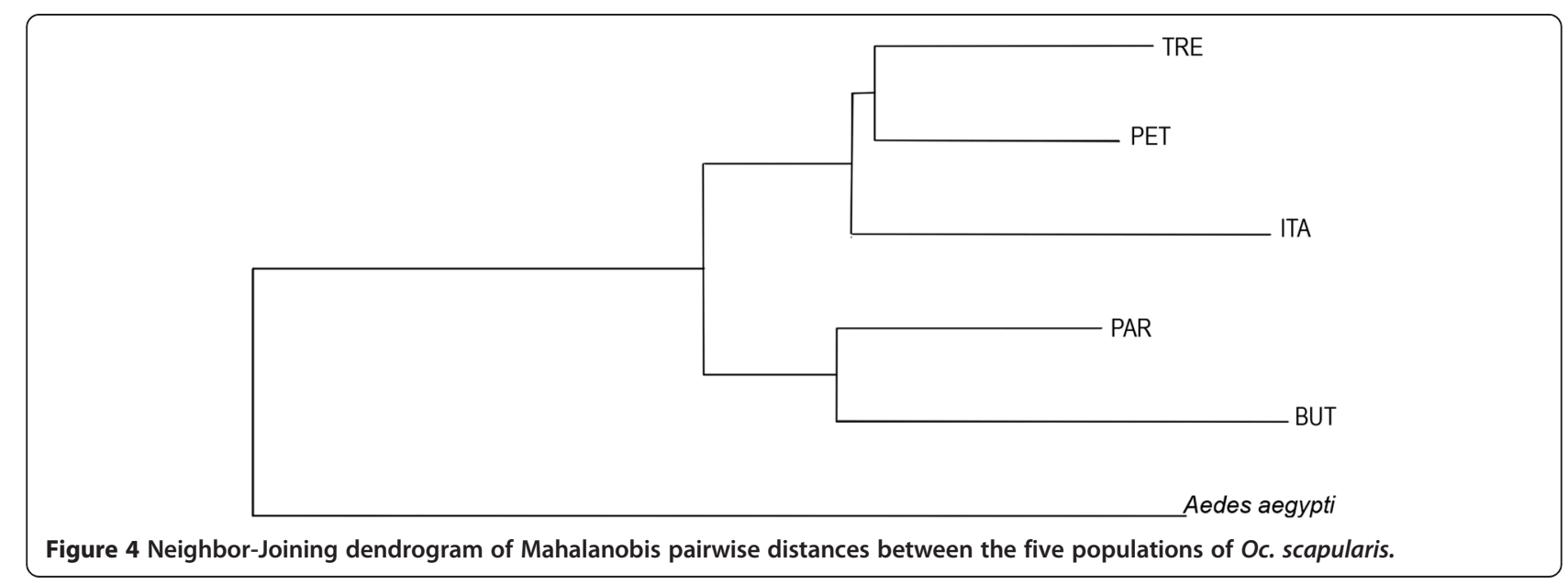




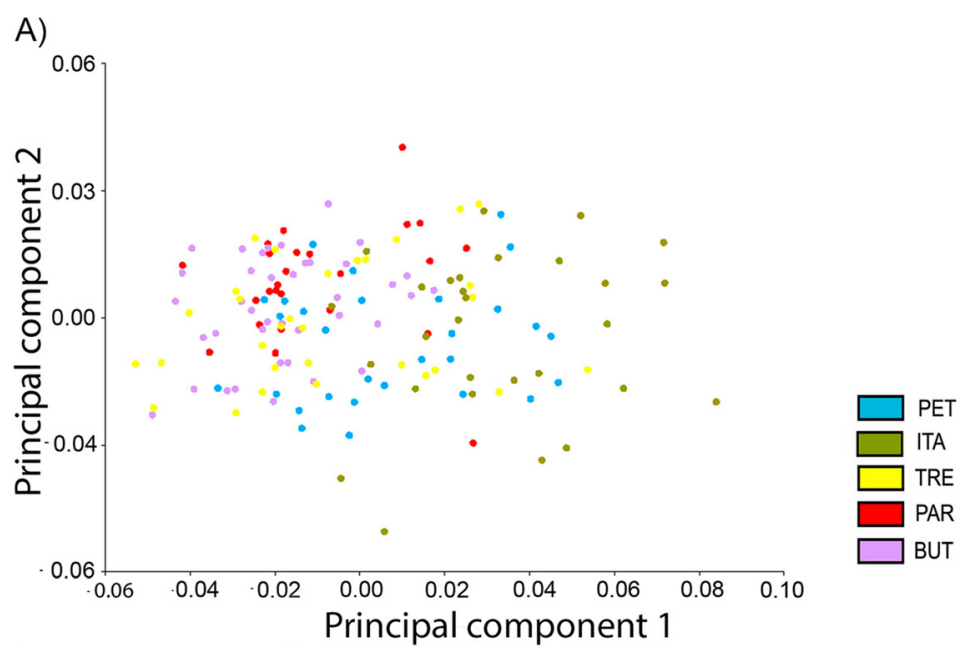

B)

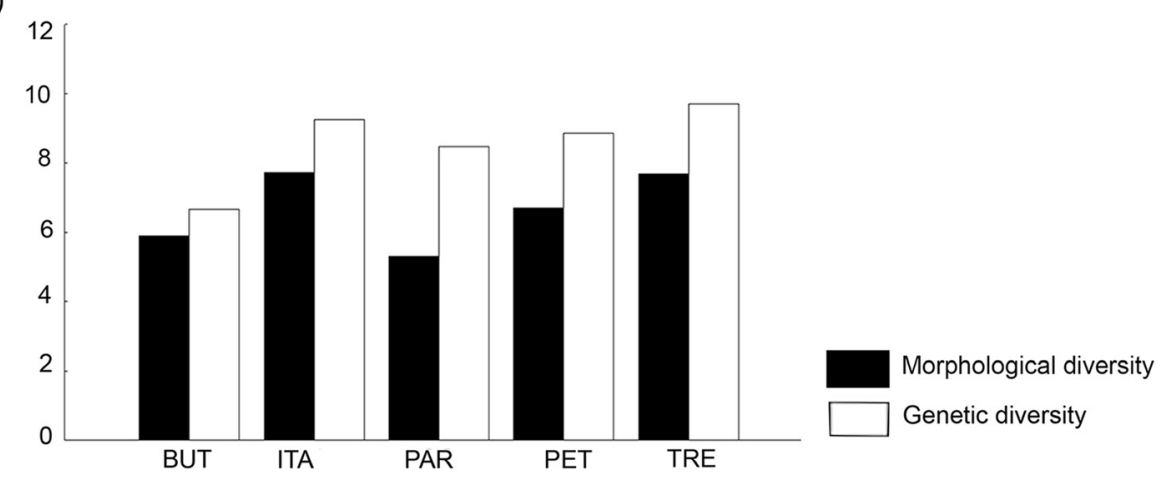

Figure 5 A Morphological space of 1 st and 2 nd shape principal components (PCs) of five populations of Oc. scapularis. B Comparison between haplotype diversity and morphological diversity of five populations.

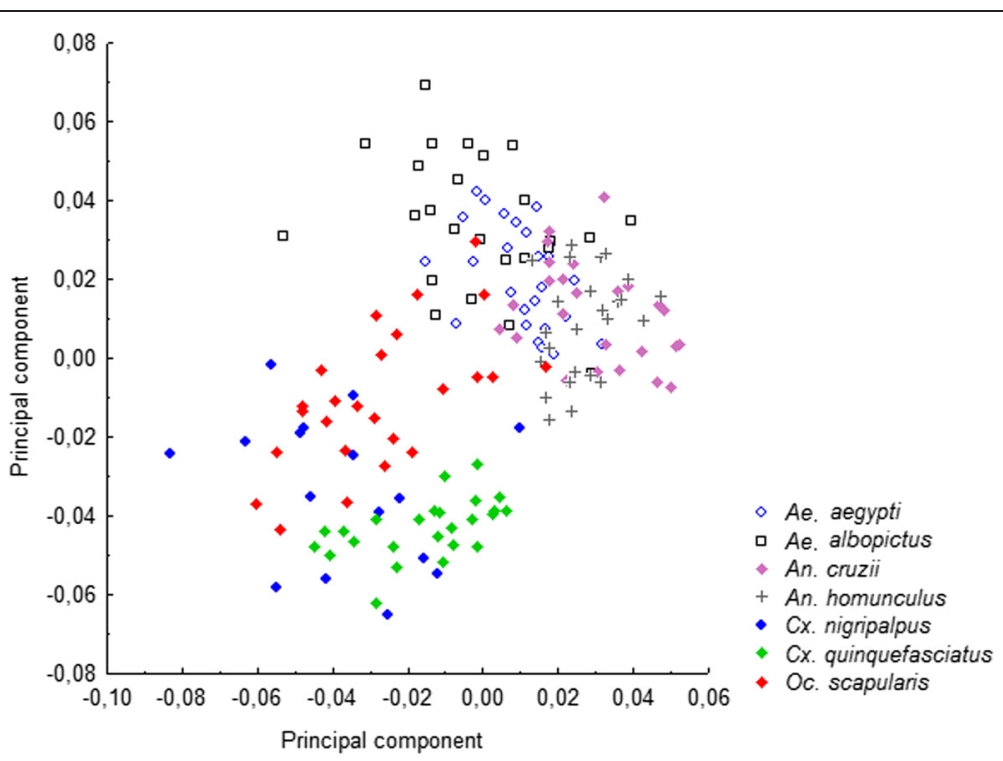

Figure 6 Comparative Morphological diversity of Oc. scapularis, Ae. aegypti, Ae. albopictus, An. cruzii, An. homunculus, Cx. nigripalpus and $C x$. quinquefasciatus. 
there was no correlation between phenetic and geographic distances. For instance, ITA and PET clustered together despite being the farthest localities. As this analysis is not phylogenetic we could not study in detail the evolutionary relationships between groups, but we can assume that the evolution of wing shape did not follow an isolation by distance pattern.

\section{Markers combined}

Results from the analyses of wing shape and COI variability were consistent but not identical. While both markers indicated slight populational differentiation, divergence derived from wing shape was more conspicuous. In fact, no statistical correlation was noted between the phenetic and genetic distances $(r=0.69$, $\mathrm{p}=0.19$ ). Apparently, wing shape is less evolutionarily stable than the COI gene, as previously hypothesized by other authors [50]. Despite the suspected congruence between genetics and phenetics, the current results reinforce the idea that wing geometry bears informative biological markers that are sensitive to microevolutionary processes and can be considered as preliminary indicators of population structure. Other authors also share this point of view $[16,50,51]$.

Accordingly, wings and COI revealed high morphogenetic variability (both intra and interpopulational). This was unexpected because the Atlantic Forest, the original habitat of this species, has been highly degraded in the past three centuries. This finding led us to pose a new hypothesis: Such biological richness might contribute to plasticity or a broad adaptation capacity of this species. This conjecture is in accordance with the findings from previous studies on Oc. scapularis, suggesting that they have vectorial competence $[8,11]$, ability to breed in artificial containers [6], tendency to occur in urban locations (PET and BUT samples), and the potential to exhibit endophily and synanthropy when present in rural or semi-rural environments [48]. Further investigations are necessary to confirm our proposed hypothesis.

\section{Conclusion}

We found many morphogenetic polymorphisms in the studied populations of Oc. scapularis, despite the species being from a fragmented habitat. Wing shape denoted incipient population structure and showed that this species is morphologically more diverse than other sylvatic Neotropical culicids. Unfortunately, studies on $O c$. scapularis are still rare despite its possible epidemiological relevance. Future investigations need to be performed to better understand the structure and dynamics of the biological variability of this species as well as the possible implications of this variability on the plasticity, synanthropy, and vectorial capacity of this species.

\section{Additional files}

Additional file 1: Figure S1. Morphological diversity estimated using the "amount of dispersion" of individuals in the morphospace of PCs. Each plots in the morphospace of PCs corresponding to a single mosquito were digitized using TpsDig software in order to register their positional coordinates in an imaginary Cartesian plane. The centroid size of a set of individuals (a population) was calculated using TpsRelW software. Such centroid size was then considered as an indicator of the morphological diversity of a population. Theoretically, the amount of dispersion of individuals (of a single set) in the morphospace of PCs is proportional to the morphological variability of that set. Subgraphs upper left of total PCs graph represents dispersion points of PAR population; Subgraphs upper right of total PCs graph represents dispersion point of ITA populations; Subgraphs lower left of total PCs graph represents dispersion points of BUT populations; Subgraphs lower of total PCs graph represents dispersion points of PET populations; Subgraphs lower right of total PCs graph represents dispersion points of PET populations; Subgraphs lower right of total PCs graph represents dispersion points of TRE populations.

Additional file 2: Table S1. Data of samples of Aedes aegypti, Aedes albopictus, Anopheles cruzii, Anopheles homunculus, Anopheles strodei, Anopheles nigripalpus, and Culex quinquefasciatus collected in Brazil.

\section{Abbreviations}

BUT: Butantan; COI: Cytochrome oxidase subunit I; DT: Tajima's D test: FS: Fu's Fs test; $F_{\text {st: }}$ The genetic differentiation index; $H$ : Number of haplotypes; H: Haplotype diversity; ITA: Itaboraí; PAR: Pariquera-Açu; PET: Parque ecológico do Tietê; $Q_{s t}$ : Quantitative trait differentiation index.; TRE: Tremembé; $\pi$ : Nucleotide diversity.

\section{Competing interests}

The authors declare that they have no competing interests.

\section{Authors' contributions}

LS designed the study. VP and MD performed collections and analysed the data. LS and VP drafted and edited the manuscript. All authors reviewed and approved the final manuscript.

\section{Acknowledgements}

This study received financial support from the Conselho Nacional de Desenvolvimento Científico e Tecnológico (CNPq grants \#136597/2009-2), Coordenação de Aperfeiçoamento de Pessoal de Nível Superior (CAPES grants \#23038.005274/2011-24 and \#1275/2011) and Fundação de Amparo à Pesquisa do Estado de São Paulo (FAPESP grants \#2006/02622-5 and 2010/ 14479-8). We thank Prof ${ }^{a}$. Dr ${ }^{a}$. Maria Anice Sallum for permitting VP and MD to use her laboratory for the development of molecular biology techniques.

\section{Author details}

${ }^{1}$ Instituto Butantan, São Paulo, Brazil. ${ }^{2}$ Biologia da Relação

Patógeno-Hospedeiro-Universidade de São Paulo, São Paulo, Brazil.

${ }^{3}$ Programa de Pós- graduação do Instituto de Medicina Tropical,

Universidade de São Paulo, São Paulo, Brazil.

Received: 15 July 2014 Accepted: 13 February 2015

Published online: 26 February 2015

\section{References}

1. Foratinni OP. Culicidologia Médica: Identificação, Biologia, Epidemiologia. São Paulo: Editora da Universidade de São Paulo Press; 2002.

2. Forattini OP, Kakitani I, Massad E, Marucci D. Studies on mosquitoes (Diptera: Culicidae) and anthropic environment: 9- Synanthropy and epidemiological vector role of Aedes scapularis in South-Eastern Brazil. Rev Saude Publica. 1995;29:199-207.

3. Dorvillé LFM. Mosquitoes as bioindicators of forest degradation in southeastern Brazil, a statistical evaluation of published data in the literature. Stud Neotropical Fauna Environ. 1996:31:68-78.

4. Silva AM, Menezes RMT. Occurrence of Aedes scapularis (Diptera: Culicidae) in artificial breeding area of Southern Brazil. Rev Saude Publica. 1996;30:103-4. 
5. Klein TA, Lima JB, Tang AT. Seasonal distribution and diel biting patterns of culicine mosquitoes in Costa Marques, Rondônia, Brazil. Mem Inst Oswaldo Cruz. 1992;87:141-8.

6. Forattini OP, Kakitani I, Sallum MAM. Breeding places of Aedes scapularis (Diptera: Culicidae) in artificial containers. Rev Saude Publica. 1997;31:519-22.

7. Mitchell CJ, Forattini OP. Experimental transmission of Rocio encephalitis virus by Aedes scapularis (Diptera: Culicidae) from the epidemic zone in Brazil. J Med Entomol. 1984;21:34-7

8. Ivesson LB. Aspects of the encephalitis epidemic caused by arbovirus in the Ribeira Valley, S. Paulo, Brazil, during 1975-1978. Rev Saude Publica. 1980;14:9-35.

9. Lourenço-de-Oliveira R, Deane LM, Lourenço-de-Oliveira R, Deane LM. Presumed Dirofilaria immitis infections in wild-caught Aedes taeniorhynchus and Aedes scapularis in Rio de Janeiro, Brazil. Memórias Inst Oswaldo Cruz. 1995;90:387-8

10. Rachou RG, Lima MM, Neto JAF, MARTINS CM. Inquérito epidemiológico de filariose bancroftiana em uma localidade de Santa Catarina. Como fase preliminar de uma prova profilática. Constatação de transmissão extradomiciliária por um novo vetor, Aedes scapularis. Ver Bras Malario Doenças Trop. 1995;7:51-70.

11. Mitchell CJ, Monath TP, Sabattini MS, Cropp CB, Daffner JF, Calisher CH, et al. Arbovirus investigations in Argentina, 1977-1980. II. Arthropod collections and virus isolations from Argentine mosquitoes. Am J Trop Med Hyg. 1985;34:945-55.

12. Pauvolid-Corrêa A, Kenney JL, Couto-Lima D, Campos ZMS, Schatzmayr HG, Nogueira RMR, et al. Ilheus virus isolation in the Pantanal, west-central Brazil. PLoS Negl Trop Dis. 2013;7:1-8.

13. Spence $L$, Anderson CR, Aitken THG, Downs WG. Melao virus, a new agent isolated from Trinidadian mosquitoes. Am J Trop Med Hyg. 1962;11:687-90.

14. de Deus JT, Kakitani I. Paridade de Ochlerotatus scapularis em condições de laboratório e campo. Rev Saude Publica. 2006;40:505-12.

15. Arnell JH. Mosquito studies (Diptera, Culicidae). XXXIII. A revision of the scapularis group of Aedes (Ochlerotatus). Contrib Amer Entomol Inst. 1976;13:1-44.

16. Vidal PO, Suesdek L. Comparison of wing geometry data and genetic data for assessing the population structure of Aedes aegypti. Infect Genet Evol. 2012;12:591-6

17. Kamgang B, Brengues C, Fontenille D, Njiokou F, Simard F, Paupy C. Genetic structure of the tiger mosquito, Aedes albopictus, in Cameroon (Central Africa). PLoS One. 2011;6:1-13.

18. Paupy C, Le Goff G, Brengues C, Guerra M, Revollo J, Barja Simon Z, et al. Genetic structure and phylogeography of Aedes aegypti, the dengue and yellow-fever mosquito vector in Bolivia. Infect Genet Evol. 2012;12:1260-9.

19. Demari-Silva B, Vesqueiro FT, Sallum MAM, Marrelli MT. Taxonomic and phylogenetic relationships between species of the genus Culex (Diptera: Culicidae) from Brazil inferred from the cytochrome c oxidase I mitochondrial gene. J Med Entomol. 2011;48:272-9.

20. Rosero DA, Jaramillo LM, Gutiérrez LA, Conn JE, Correa MM. Genetic diversity of Anopheles triannulatus s.l. (Diptera: Culicidae) from northwestern and southeastern Colombia. Am J Trop Med Hyg. 2012;87:910-20.

21. Endersby NM, White VL, Chan J, Hurst T, Rašić G, Miller A, et al. Evidence of cryptic genetic lineages within Aedes notoscriptus (Skuse). Infect Genet Evol. 2013;18:191-201

22. Pedro PM, Uezu A, Sallum MAM. Concordant phylogeographies of 2 malaria vectors attest to common spatial and demographic histories. J Hered. 2010;101:618-27

23. Folmer $\mathrm{O}$, Black M, Hoeh W, Lutz R, Vrijenhoek R. DNA primers for amplification of mitochondrial cytochrome c oxidase subunit I from diverse metazoan invertebrates. Mol Mar Biol Biotechnol. 1994;3:294-9.

24. Technelysium Pty Ltd. [http://www.technelysium.com.au/chromas_lite.html].

25. Rozas J, Sánchez-DelBarrio JC, Messeguer X, Rozas R. DnaSP, DNA polymorphism analyses by the coalescent and other methods. Bioinformatics. 2003;19:2496-7.

26. Excoffier L, Laval G, Schneider S. Arlequin (version 3.0): an integrated software package for population genetics data analysis. Evol Bioinforma Online. 2007;1:47-50

27. Tamura K, Peterson D, Peterson N, Stecher G, Nei M, Kumar S. MEGA5: molecular evolutionary genetics analysis using maximum likelihood, evolutionary distance, and maximum parsimony methods. Mol Biol Evol. 2011;28:2731-9.

28. Clement M, Posada D, Crandall KA. TCS: a computer program to estimate gene genealogies. Mol Ecol. 2000;9:1657-9.
29. Dujardin J-P. Morphometrics applied to medical entomology. Infect Genet Evol. 2008:8:875-90.

30. Demari-Silva B, Suesdek L, Sallum MAM, Marrelli MT. Wing geometry of Culex coronator (Diptera: Culicidae) from South and Southeast Brazil. Parasit Vectors. 2014;7:174-83

31. Aytekin S, Aytekin AM, Alten B. Effect of different larval rearing temperatures on the productivity (Ro) and morphology of the malaria vector Anopheles superpictus Grassi (Diptera: Culicidae) using geometric morphometrics. J Soc Vector Ecol. 2009;34:32-42

32. Henry A, Thongsripong P, Fonseca-Gonzalez I, Jaramillo-Ocampo N, Dujardin JP. Wing shape of dengue vectors from around the world. Infect Genet Evol. 2010;10:207-14.

33. Digitize Landmarks and Outline. [http:/life.bio.sunysb.edu/ee/rohlf/software.html].

34. Klingenberg CP. MorphoJ: an integrated software package for geometric morphometrics. Mol Ecol Resour. 2011;11:353-7.

35. Dujardin JP. Permutations and discriminant analises (PAD) [mpl.ird.fr/ morphometrics]

36. Swofford DL. PAUP*. Phylogenetic Analysis Using Parsimony (*and Other Methods). Version 4 [http://www.sinauer.com/paup-phylogenetic-analysisusing-parsimony-and-other-methods-4-0-beta.html].

37. Dujardin J.P. COO, MOG and COV for Windows [http://mome-clic.com/theclic-package/]

38. StatSoft, Inc.STATISTICA (data analysis software system), version 7. [http://www.statsoft.com]

39. Engdahl C, Larsson P, Näslund J, Bravo M, Evander M, Lundström JO, et al. Identification of Swedish mosquitoes based on molecular barcoding of the COI gene and SNP analysis. Mol Ecol Resour. 2014;14:478-88.

40. McKeon SN, Lehr MA, Wilkerson RC, Ruiz JF, Sallum MA, Lima JB, et al. Lineage divergence detected in the malaria vector Anopheles marajoara (Diptera: Culicidae) in Amazonian Brazil. Malar J. 2010;9:271-84.

41. Dean W. História e a devastação da Mata Atlântica brasileira. São Paulo: Companhia das Letras; 1996.

42. Werblow A, Klimpel S, Bolius S, Dorresteijn AWC, Sauer J, Melaun C. Population structure and distribution patterns of the sibling mosquito species Culex pipiens and Culex torrentium (Diptera: Culicidae) reveal different evolutionary paths. PLoS One. 2014;9:1-14.

43. Ambrose L, Riginos C, Cooper RD, Leow KS, Ong W, Beebe NW. Population structure, mitochondrial polyphyly and the repeated loss of human biting ability in anopheline mosquitoes from the southwest Pacific. Mol Ecol. 2012;21:4327-43.

44. Yang M, Ma Y, Wu J. Mitochondrial genetic differentiation across populations of the malaria vector Anopheles lesteri from China (Diptera: Culicidae). Malar J. 2011;10:216-3.

45. Morais SA, de Almeida F, Suesdek L, Marrelli MT. Low genetic diversity in Wolbachia-Infected Culex quinquefasciatus (Diptera: Culicidae) from Brazil and Argentina. Rev Inst Med Trop. 2012;54:325-9.

46. Lorenz C, Marques TC, Sallum MA, Suesdek L. Altitudinal population structure and microevolution of the malaria vector Anopheles cruzii. Parasit Vectors. 2014:7:581.

47. Gutiérrez LA, Gómez GF, González JJ, Castro MI, Luckhart S, Conn JE, et al. Microgeographic genetic variation of the malaria vector Anopheles darlingi root (Diptera: Culicidae) from Córdoba and Antioquia, Colombia. Am J Trop Med Hyg. 2010:83:38-47.

48. Beebe NW, Ambrose L, Hill LA, Davis JB, Hapgood G, Cooper RD, et al. Tracing the tiger: population genetics provides valuable insights into the Aedes (Stegomyia) albopictus invasion of the Australasian region. PLoS Negl Trop Dis. 2013;7:1-12.

49. Donnelly MJ, Pinto J, Girod R, Besansky NJ, Lehmann T. Revisiting the role of introgression vs shared ancestral polymorphisms as key processes shaping genetic diversity in the recently separated sibling species of the Anopheles gambiae complex. Heredity. 2004;92:61-8.

50. Motoki MT, Suesdek L, Bergo ES, Sallum MAM. Wing geometry of Anopheles darlingi Root (Diptera: Culicidae) in five major Brazilian ecoregions. Infect Genet Evol. 2012;12:1246-52.

51. Vidal PO, Carvalho E, Suesdek L. Temporal variation of wing geometry in Aedes albopictus. Memórias Inst Oswaldo Cruz. 2012;107:1030-4. 